\title{
Expansão da educação superior e a reforma da rede federal de educação profissional
}

\author{
Deise Mancebo \\ Universidade do Estado do Rio de Janeiro \\ João dos Reis Silva Júnior \\ Universidade Federal de São Carlos \\ Arizona State University
}

\section{Resumo}

O presente artigo discute a expansão da rede federal de educação profissional no Brasil. Considera que o crescimento dessa modalidade educacional é mais uma dimensão da marcante diversificação da educação superior, que remete à reprodução das desigualdades sociais. Trata-se de um estudo de caráter exploratório e sua construção apoia-se em pesquisa bibliográfica e análise documental necessária à compreensão do tema, em sua dimensão conceitual e histórica. Conclui, apresentando a dualidade do sistema federal de educação superior, hoje composto por universidades e a rede profissional, com objetivos, funções, controles e clientelas distintos.

Palavras-chave: Expansão da educação superior. Reforma da educação profissional. Desigualdades sociais.

\section{Expansion of higher educationandthe reform of professional education}

\section{Abstract}

This article discusses the expansion of Brazilian professional education in federal system. It considers that the growth of this educational modality is an important dimension of diversification of higher education, which refers to the reproduction of social differences. The paper is an exploratory study and its construction relies on specialized literature and document analysis needed to understand the subjecthistoricallyand conceptually. It concludes, indicating the duality of the federal higher education, composed ofuniversities andprofessionalsystem, withobjectives, functions, and different controls.

Keywords: Expansionof higher education. Professional education reform. Socialinequalities. 
Expansão da educação superior e a reforma da rede federal de educação profissional

\section{La expansión dela educación superiory la reforma dela red deforma- ción profesional}

\section{Resumo}

Este artículo seanaliza la expansión de la red federal de educación professional en Brasil. Considera que el crecimiento de esta modalidad educativa es una importante dimensión de la notable diversificación de la educación superior, que ten referencia a la reproducción de las desigualdades sociales. Se trata de un estudio exploratório y su construcción se apoya en la literatura y el análisis de documentos necesarios para compreender el tema en su dimensión conceptual y histórica. En conclusión, indica la dualidad del sistema federal de la educación superior que, en la actualidad, se compone de universidades y de la red de educación profesional, con objetivos, funciones, controles y diferentes clientelas.

Palabras clave: La expansión de la educación superior. La reforma de la educación profesional. Desigualdades sociales.

\section{Introdução}

O presente artigo propõe-se à análise da expansão da educação superior no âmbito da Rede Federal de Educação Profissional, Científica e Tecnológica. Supõe que a expansão dessa rede corresponde a mais um exemplo de uma tendência geral que tem caracterizado a educação superior no país e no mundo: a diversificação dos sistemas educacionais. Sob essa racionalidade, a educação superiorvem passando por transformações rumo a um sistema pós-secundário progressivamente diversificado, comportandofuncionalidades e arranjos institucionais diversos e, obviamente, destinados a segmentos da população também distintos.

Essa tendência internacionalé fortemente incentivada/praticamente induzida) por organismos internacionais, dentre os quais, o Banco Mundial que apresenta papel de destaque. Desde o início dos anos 1990, o Banco já vinha desenvolvendo análises sobre a falência do Estado provedor, ao que contrapunha a defesa de um Estado supervisor, com ênfase para a necessidade de modos de gestão empresariais nas instituições de ensino, onde a diferenciação detinha um papel de destaque. 
Em 1994, o Banco publica um documento seminal sobre o tema. Pelas "lições da experiência" (WORLDBANK, 1994), o ensino superior deveria se substancializar, através: a) do incentivo à expansão do setor privado; b) da busca de fontes alternativas de recursos no setor público (mensalidades, cursos pagos, consultorias, contribuição de ex-alunos), apresentadas sob o manto de autonomia financeira; c) da busca de uma maior "eficiência" interna (otimização do uso do espaço físico, aumento do número de alunos por professor); d) da criação de sistemas de medição (intitulados avaliação), pautados em critérios de produtividade, que permitissem comparação e ranqueamento, e subsidiassem a distribuição de recursos para instituições e prestadores dos serviços (pagamento por desempenho, por exemplo) e, o que aqui nos interessa, e) através da diversificação das instituições de ensino superior, o que comparece, conforme Siqueira:

[...] acompanhado de uma crítica incisiva ao modelo de ensino superior baseado na universidade de pesquisa - considerada caríssima e inadequada às necessidades e aos recursos dos países mais pobres -, bem como da defesa da criação de instituições de ensino superior não-universitárias (SIQUEIRA, 2004, p. 50).

O assunto retorna em documento do Banco Mundial de 1999, no qualé adotada a terminologia "sociedade do conhecimento", para indicar que níveis mais elevados de educação seriam fundamentais para o desenvolvimento e competitividade das nações num mundo globalizado. Adicionalmente, - Banco (WORLDBANK, 1999) retoma com maior intensidade a necessidade de abertura dos sistemas de ensino superior ao setor privado internacional e a grandes firmas nacionais a ele associados, e novamente enfatiza a necessidade de diversificação das instituições,

[...] com o estabelecimento de um sistema estratificado, com poucas universidades de pesquisa no topo, seguidas por universidades de formação profissional de quatro anos, e institutos isolados e centros vocacionais e/ou de formação técnica com duração de dois anos. As universidades de pesquisa deveriam atender à elite intelectual do país, contar prioritariamente com verbas públicas, ser gratuitas, mas usar seu potencial para o desenvolvimento, isto é, fazer projetos com o intuito de acelerar o desenvolvimento econômico do país e a competitividade das empresas. Já o nível mais baixo no ranking, os cursos pós-secundários elevados à categoria 
Expansão da educação superior e a reforma da rede federal de educação profissional

de nível superior, destinados aos mais pobres, deveriam ser pagos e oferecidos pelo setor privado. Também se reforçam novas modalidades de oferta do ensino superior, como o ensino a distância, o semipresencial, bem como sua oferta em blocos sequenciais (SIQUEIRA, 2004, p. 51 ).

Revisitar esses textos do Banco, o primeiro dos quais já com 20 anos de publicação, é ilustrativo, pois indica que, no Brasil, boa parte da "cartilha" foi seguida. No que tange ao tema desta introdução, pode-se atestar que, a partir dos anos de 1990, a tendência à diversificação do sistema de educação superior não parou de se aprofundar, a começar pelo capítulo "Da Educação Superior", da Lei de Diretrizes e Bases da Educação Nacional -Lei n 9.394, de 20 de dezembrode 1996 (BRASIL, 1996) -que, nos artigos 43 a 57, aponta para a diferenciação e flexibilizaçãoda oferta nesse nível de ensino.

A tendência não parou de deitar raízes, de modo que, atualmente, pode-se assistir, além da diversificação dos tipos institucionais, à diversificação das modalidades terminais (diplomas e certificados), de cursos e programas nas diferentes modalidades (a distância, semipresenciais); à diversificação e diferenciação no tocante à adoção de formatos e modalidades diferentes na 76 organização institucional e acadêmica, com cursos de ensino superior que visam formar profissionais para atender a campos específicos do mercado de trabalho, com formato compacto e duração média menor que a dos cursos de graduação tradicionais (sequenciais, por exemplo); às tendências de internacionalização da educação superior e, no que aqui mais interessa, à institucionalização da Rede de Educação Profissional, com a criação dos Institutos Federais de Educação, Ciência e Tecnologia (IFs); dentre outras possibilidades (MANCEBO, 2010).

Em síntese, ocorre todo um novodirecionamento da educação superior, já designada oficialmente como "educação terciária" - termo proposto pelo próprio Banco Mundial, em publicação de 2003 - que ressignifica a educação superior como ensino pós-secundário. Isto parece afetar especialmente o trabalho do professor e a formação que, com muita facilidade, pode ser deslocada para mera capacitação ou até mesmo reciclagem.

Em nome da "educação terciária", o Banco Mundial reivindica o aprofundamento da diversificação das instituições de ensino superior, dos cursos, currículos, dando ênfase ao ensino de graduação (o mais aligeirado possível), 
desvinculado da pesquisa e da produção crítica e criativa do conhecimento, mas organicamente vinculado ao mercado e suas demandas.

Este texto discute um dos braços desta diversificação: a expansão do ensino profissional e tecnológico no Brasil, mais especificamente, na rede federal de educação superior. Trata-se de um estudo de caráter exploratório e sua construção apoia-se em pesquisa bibliográfica e análise documental de temas convergentes e necessários para a compreensão do tema, adotando uma perspectiva de análise que conjuga aspectos quantitativos e qualitativos.

Para tal,o texto organiza-se em três partes: apresenta a concepção teórica da relação trabalho/educação que norteiaa discussão; expõe, sinteticamente, a evolução histórica da educação profissional no país,e, por fim, analisa, criticamente, a recente reestruturação da Rede Federal de Educação Profissional, Científica e Tecnológica.

\section{Concepção de trabalho/educação}

Mèszàros, em seu clássico, Marx: a teoria da alienação, de 1981 , traz uma distinção importante para a compreensão do conceito de trabalho em Marx. $\bigcirc$ autor estabelece uma distinção entre trabalho como mediação de primeira ordem, processo entre o homem e a natureza e que corresponde à compreensão ontológica de trabalho, e a mediação de segunda ordem, para designar as formas históricas que o trabalho assume.

Como Mèszàros(1981), considera-se, neste texto, que o trabatho em sua dimensão ontológica é a categoria constitutiva do ser social (LUKÁCS, 1979), pois diferentemente dos demais animais, que são regulados e programados por sua natureza, e por isso não projetam sua existência, não a modificam, mas se adaptam e respondem instintivamente ao ambiente, os seres humanos criam e recriam, pela ação consciente do trabalho (dimensão, portanto, invariavelmente, teleológica), a sua própria existência. Na expressão do próprio Marx (1983):

Antes, o trabalho é um processo entre o homem e a natureza, um processo em que o homem, por sua própria ação, medeia, regula e controla seu metabolismo com a natureza. Ele mesmo se defronta com a matéria natural como uma força natural. Ele põe em movimento as forças naturais pertencentes à sua corporeidade, braços, 
Expansão da educação superior e a reforma da rede federal de educação profissional

pernas, cabeça e mãos, a fim de se apropriar da matéria natural numa forma útil à própria vida. Ao ałuar, por meio desse movimento sobre a natureza externa a ele e ao modificá-la, ele modifica, ao mesmo tempo, sua própria natureza (MARX, 1983, p. 149).

Deste modo, independente de qualquer forma de sociedade, o trabalho, ontologicamente considerado, é uma condição de existência da humanidade. Eleé uma necessidade eterna que tem a função de mediar o intercâmbio entre o homem e a natureza, que possibilita a própria vida dos homens, que permeia todo o ser do homem e constitui a sua especificidade. Assim, o trabalho enquanto mediação de primeira ordem é o processo coletivo, mediante o qual o ser social produz as condições gerais da existência humana, incluindo a educação, a produção de conhecimentos e saberes.

A discussão sobre a ontologia do ser social é fundamental, especialmente a exposta na obra de Lukács (1979). Todavia à dimensão ontocriativaé necessárioacrescentar a análise das formas históricas dotrabalho-mediação de segunda ordem em Mészáros (1981)-, para que se possa indagar, a relação do estrutural e conjuntural, no tempo e no espaço, nas mediações e contradi78 coões sing

A dimensão histórica do trabalho, então, envolve a análise das características específicas e determinadasassumidas pelo trabalho, conforme as diferentes relações sociais de produção construídas ao longo da história da humanidade e, portanto, dos diversos modos de produção.

No modo de produção capitalista, o trabalho assume um duplo aspecto: produz mercadoria que possui necessariamente valor de uso, ou seja, aquela que é capaz de satisfazer necessidades humanas e, ao mesmo tempo, produz mercadoria enquanto veículo material de um valor de troca, necessário ao próprio processo de reprodução e valorização do capital. Em síntese, " [...] esta dimensão contraditória do trabalho representa a sua forma histórica degradada e alienada sob o domínio das relações capitalistas de produção" (LIMA FILHO, 2010 , p. 89).

As concepções, teorias e políticas relativas à educação também só ganham sentido histórico quando apreendidas no conjunto de relações sociais de produção e dentro de um determinado contexto. Assim, em cada modo de produção, as diferentes sociedades elaboram formas próprias de educação, 
que correspondem "[...] às demandas de cada grupo e das funções que thes cabe desempenhar na divisão social e técnica do trabalho"|KUENZER; GRABOWSKI, 2006, p. 2991.

Para nossa discussão, é importante destacar que foi, ao longo da ditadura, que se introduziu e se assimilou, no Brasil, de forma submissa, a ideologia do capital humano, formulada por Schultz (1973). Sob esse desenvolvimento teórico, efetivaram-se reformas educacionais no país da pré-escola à pós-graduação, reduzindo a educação de direito social inalienável e subjetivo a um fetiche mercantil.

Na década de 1990, no entanto, a ideologia do capital humano é revista para fazer coro a um contexto de mundialização do capital, a mudanças ocorridas no mundo do trabalho a partir da substituição da base rígida pela base flexível, a reformas que consubstanciavam o desmanche do Estado na sua face social,ao intenso processo de dilapidação do patrimônio público por meio das privatizações e às inúmeras tentativas de desmonte das organizações dos trabalhadores para enfraquecê-las frente ao capital e deixar caminho aberto à espoliação. Como sempre sucede, o sucesso desta profunda reengenharia social dependia de uma investida no campo das ideias. Impunham-se novas formas de disciplinamento da força de trabalho, sobre a qual se abatia os resultados do acelerado processo de destruição e reconstrução de habilidades, os níveis crescentes de desemprego estrutural, a redução dos salários e a desmobilização sindical. Fazia-se necessária a criação de um consenso conformista nas massas, que reforçasse a doutrina do livre mercado, da competição, da busca do sucesso individual e do empreendedorismo individual como ideal de relações humanas.

Os processos educativos, constituídos e constituintes do modo dominante da sociedade, são chamados a cooperar novamente com a produção de subjetividades que atendessem às novas exigências da produção e da vida social, mas também queestivessem dispostas a se submeter aos processos flexíveis e instáveis do trabalho e da vida.

Conforme análise de Frigotto e Ciavatta (201 1, p. 624), neste novo rearranjo do capitalismo, a teoria de Schultz (1973) é revisitada e "[...] a ideologia do capital humano se redefine, mediante as noções de sociedade do conhecimento, qualidade total, pedagogia das competências, empregabilidade e empreendedorismo." 
Expansão da educação superior e a reforma da rede federal de educação profissional

Essa importante redefinição teórica intensifica a competição e uma dimensão individualista de formação e induz...

[...] à formação aligeirada [...] em cursos pragmáticos, tecnicistas e fragmentados ou a treinamentos breves de preparação para o trabalho simples, forma dominante a que somos condenados na divisão internacional do trabalho. $\mathrm{E}$, de acordo com as necessidades do mercado, prepara-se uma minoria para o trabalho complexo (FRIGOTTO; CIAVATTA, 201 1, p. 624).

Pode-se afirmar, portanto, que, no regime de acumulação flexível (HARVEY, 1992), a despeito da ideologia da "sociedade do conhecimento", as desigualdades educacionais não são amenizadas, ao contrário, aprofundam-se as diferenças de classe e a dualidade estrutural, no âmbito da própria escola, mediante a polarização das competências.

Essa dinâmica educacional permeou toda a década de 1990 e os governos de Lula da Silva (2003-20 10) e Dilma Roussef (201 1-20 14) deram continuidade a essas políticas, de corte neoliberal. Frustraram-se as expectativas de mudanças estruturais na sociedade e na educação, pautadas nos 80 direitos inscritos na Constituição Federal de 1988, que não se realizaram, mesmo que tenham criado algumas mudanças pontuais em atendimento às pressões de setores da sociedade civil organizada. $\bigcirc$ resultado foi:

[...] um quadro ambíguo de políticas educacionais, em grande parte orientadas pelos organismos internacionais, outras resultantes de pressões sociais dos setores mais atuantes em defesa da elevação de escolaridade e da educação profissional dos trabaIhadores; outras, particularmente, a partir dos setores empresariais e do Sistema S, demandando a formação estrita de mão de obra (FRIGOTTO; CIAVATTA, 201 1, p. 626).

Obviamente, ao longo de todo esse período, embates teóricos e ideológicos ocorreram no campo educacional. No caso específico da formação profissional e tecnológica, merece menção a concepção da educação politécnica, que se contrapôs às visões do tecnicismo, do adestramento e da polivalência. Esse olhar contra-hegemônicosobre a educação implicava uma nova compreensão sobre os alunos, aqui entendidos como sujeitos que detêm conhecimentos (alguns oriundos do trabalho) e que são capazes de se apropriar do conhecimento científico e criar, mediante o exercício do pensamento 
crítico, condições de autonomia intelectual e crítica. Envolve, ainda, a articulação entre trabalho intelectual e trabalho manual, uma formação que emana do próprio trabalho social, e que permite compreender o funcionamento da sua organização na nossa sociedade.

Obviamente, para tal, faz-se "[...] necessário construir estratégias metodológicas apropriadas e apreensíveis para as classes populares, que respondam às suas reais necessidades, no sentido de garantir a permanência e a conclusão com qualidade" (LIMAFILHO, 2011 , p. 738). Alguns pesquisadores têm ousado fazer essas construções e têm tratado com profundidade as concepções e princípios que fundamentam a proposta de "[...] currículo integrado, explicitando suas possibilidades, sem deixar de problematizar as dificuldades de implementá-lo [bem como o próprio conceito de politecnia] numa sociedade de classes como a brasileira" (LIMA FILHO, 201 1, p. 731 ).

De todo modo, cabe o registro de que, em contraposição à perspectiva hegemônica e instrumental da formação, particularmente forte na educação profissional, que toma o mercado como instrumento regulador da sociabilidade humana, há, por outro lado, outra formulação teórica em disputa, que vem sendo construída em defesa de uma escola unitária, voltada aos interesses da classe trabalhadora, na qual a educação profissional é considerada com "[...] uma sólida base de educação geral, científico-tecnológica e sócio-histórica" (KUENZER; GRABOWSKI, 2006, p. 297).

\section{Breve história da educação profissional no Brasil}

A história da educação profissional no Brasil é marcada, desde a sua origem, com o Decreto-Lei n 7.566, de 23 de setembro de 1909, do então presidente Nilo Peçanha (BRASIL, 1909), pelo oferecimento de uma escolarização simplificada, pela insuficiência de recursos e pela organização de currículos e modelos educacionais de adestramento para o trabalho. Tal simplificação é produzida para o atendimento do mínimo necessário ao que é requerido pelas necessidades de acumulação do capital em cada conjuntura. Com essas características, ao longo do século XX, " [... ] desenvolveu-se uma extensa e diversificada oferta de educação profissional, com o intuito de atender às demandas decorrentes da expansão dos setores industrial, comercial e 
Expansão da educação superior e a reforma da rede federal de educação profissional

de serviços, que se intensificou a partir dos anos de 1940" (KUENZER, 2007, p. 1156$)$.

Deve-se destacar que as escolas de formação profissional em diferentes níveis são criadas paralelamente à rede de escolas destinadas à formação propedêutica, atendiam populações com diferentes origens de classe e definiam, assim, uma das facetas do caráter de classe da educação brasileira. Nas análises de Kuenzer:

A delimitação precisa das funções operacionais, técnicas, de gestão e de desenvolvimento de ciência e tecnologia, típicas das formas tayloristas/fordistas de organizar o trabalho, viabilizava a clara definição de trajetórias educativas diferenciadas que atendessem às necessidades de disciplinamento dos trabalhadores e dirigentes (KUENZER, 2007, p. 1156 ).

Para os futuros trabalhadores, não era requerida uma escolarização geral e ampliada, uma vez que não havia necessidades significativas de trabalho intelectual. A eles bastaria "uma educação profissional especializada, parcial, com foco na ocupação e voltada para o rigoroso cumprimento de 82 procedimentos a serem repetidos por meio de processos pedagógicos que privilegiavam a memorização" (KUENZER, 2007, p. 1157).

Aimplantação doscursos superiores de tecnologia só ocorreu na década de 1960 e visava, declaradamente, atender ao mercado de trabatho emergente.A primeira experiência surgiu em São Paulo, em 1963, com o Curso de Engenharia de Operação, com duração de três anos, para atender a demandas da indústria, em crescente desenvolvimento e com necessidade de absorver profissionais mais especializados.

Todavia, conforme Sousa (2013), foi com a Lei n 5.540, de 28 de novembro de 1968, conhecida como Lei da Reforma Universitária (BRASIL, 19681, que ocorreu a formalização para a criação dos cursos profissionais superiores. "Em termos práticos, a Lei em destaque propunha cursos superiores de curta duração, concebidos de maneira geral e para diferentes áreas do conhecimento, apoiando-se no argumento de que tais cursos deveriam fazer facea peculiaridades do mercado de trabalho regional (artigo 18)" (SOUSA, 2013 , p. 1911.

Assim, nos anos de 1970, "ganha força a intenção do Estado em inserir, em um curto prazo, pessoal qualificado no mercado de trabalho com 
o objetivo de atender à diversificação e especialização das tarefas decorrentes do crescimento industrial" (SOUSA, 2013, p. 193). Deve-se, no entanto, elencar, pelo menos, mais três ordens de problemas que justificavam o interesse da ditadura civil-militar na implantação desses cursos, na década de 1970, no país: (1) problemas políticos, em decorrência das pressõesdo movimento estudantil visando à ampliação de vagas e de verbas para a educação superior, especialmente forte de 1964 a 1968; (2) problemas sociais, advindos de grupos diversos das camadas médias da população, que se frustravam, profissionalmente, com a formação superior regular, por não obterem empregos nos parâmetros desejados e (3) problemas financeiros, relacionados à necessidade de expansão da educação superior pública, mas com racionalização de recursos (PETEROSSI, 1980).

Todavia, a crise econômica desencadeada a partir do final dos anos de 1970, impede o aumento desses cursos na esfera pública, como projetado pelos governos militares, e a expansão da rede superior profissional e tecnológica só ocorre de forma mais significativa nasinstituições privadas. Fato é que, em meados dos anos de 1990, se podia contabilizar no país, apenas cinco Centros Federais de Educação Tecnológica (CEFET), localizados na Bahia, Maranhão, Minas Gerais, Paraná e Rio de Janeiro, que ofereciam, à época, um total de 15 desses cursos (SOUSA, 2013, p. 196).

Somente, com a promulgação da Lei n 9.394, Lei de Diretrizes e Bases da Educação Nacional, em de 20 de dezembro de 1996 (BRASIL, 1996), a educação profissional ganha novo alento. No capítulo III, onde a matéria é regulamentada, é explícita a relevância dada ao domínio da tecnologia e dos princípios científicos e tecnológicos que presidem a produção moderna.

A promulgação da LDB desencadeia, ainda, um expressivo aparato legal visando subsidiar a oferta e expansão dos cursos superiores de formação profissional e tecnologia. Cabe destaque ao Decreto n ${ }^{\circ} 2.208$, de 17 de abril de 1997 (BRASIL, 1997) que provoca profundas mudanças nessa modalidade de ensino. Primeiramente, ele estabelece os níveis da educação profissional: (1) nível básico, destinado à qualificação, requalificação e reprofissionalização de trabalhadores, independente de escolaridade prévia; (2) nível técnico: destinado a proporcionar habilitação profissional a alunos matriculados ou egressos do ensino médio e (3) nível tecnológico, correspondente a cursos de nível superior na área tecnológica, destinados aos egressos do ensino médio 
Expansão da educação superior e a reforma da rede federal de educação profissional

e técnico (BRASIL, 1997). Todavia, os grandes retrocessosimpetrados por esse Decreto no campo educacional residiram na determinação deseparar, novamente, educação geral e profissional, na promoçãodo aligeiramento desta modalidade educacional e na induçãoque vinculaa educação profissionala objetivos estritos do mercado. Todo esse processo acentuou, ainda mais, um quadro de desigualdade social e educacional, sobretudo, para jovens e adultos trabalhadores (LIMA FILHO, 2011 ) ea dualidade entre uma formação básica, mais plena, e uma formação profissional, rápida edestinada ao atendimento ao mercado de empregos. Obviamente, setores da comunidade educacional questionaram as novas diretrizes e

[...] pressionaram, desde o início do mandato presidencial de Lula da Silva, por novos encaminhamentos de políticas na perspectiva da formação humana e da inclusão social. Buscava-se, por um lado, o resgate do direito à educação aos trabalhadores excluídos da escola e, por outro, a superação de um marco legal-institucional que separava a educação básica da formação profissional (LIMA FILHO, 2011 , p. 728).

Como resposta a essa pressão, nova regra é estabelecida, com o Decreto $n^{\circ}$ 5. 154, em 23 de julho de 2004 (BRASIL, 2004), que revoga o de 1997 e restabelece a possibilidade da organização curricular integrada de educação profissional e educação geral.

Ainda no ano de 2004, todos os Cefets ascenderam à situação de instituições de educação superior, pelo Decreto n 5.225, de $1^{\circ}$ de outubro de 2004 (BRASIL, 2004a) com autonomia equivalente à das universidades. Conforme Otranto (2012, p. 202), esta medida"[...] gerou um interesse crescente nas demais instituições de educação profissional, principalmente nas Escolas Agrotécnicas e Escolas Técnicas [...], de alcançarem esta mesma condição [... .", clima que se intensificou a partir de 2005, quando o Cefet Paraná foi, de fato, transformado em Universidade Tecnológica do Paraná.

Todavia, à revelia da vontade dessas instituições, os planos governamentais encaminharam-se em sentido bem diverso e,apesar das pressões, o governo Lula preparava uma Reforma da Educação Profissional que não previa a transformação dessas instituições em universidade, mas em Institutos Federais de Educação, Ciência e Tecnologia (IFs). Essas instituições são de custos bem mais modestos, fazendo coro à diversificação apregoada pelo Banco Mundial, desde a década de 1990 (OTRANTO, 2012). 
A apresentação dessa breve história ilustra vários momentos de tensão entre distintas concepções (e propostas) educacionais para a formação profissional. Indica que ao projeto hegemônico contrapuseram-se compromissos educacionais, que apontaram para a necessidade de uma educação profissional ampliada e de qualidade, para todos os que vivem do trabalho.

\section{Reforma da educação profissional e tecnológica}

Recentemente, novas e profundas mudanças vêm ocorrendo na educação profissional brasileira, especialmente, a partir do segundo mandato do ex-presidente Lula da Silva.

Sinteticamente, pode-se afirmar que a reforma da educação profissional e tecnológica está se desenvolvendo em duas grandes frentes. Primeiramente, a que foi instituída pela Lei $n^{\circ} 11.892$, de 29 de dezembro de 2008, que cria os Institutos Federais de Educação, Ciência e Tecnologia (IFs) e afeta diretamente a educação superior do país. Mais recentemente, surge uma segunda regulação, com a sanção pelapresidenta Dilma Rousseff da Lei $n^{\circ}$ 12.513,em 26 de outubro de 201 1, que institucionaliza o Programa Nacional de Acesso ao Ensino Técnico e Emprego (Pronatec). Esse programa se propõe à expansão, interiorização e democratizaçãoda oferta de cursos de educação profissional técnica de nível médio presencial e a distância e de cursos e programas de formação inicial e continuada ou qualificação profissional.

Pelo recorte eleito neste texto (a educação superior), será analisada somente a primeira legislação, concretizada pela Lei no 11.892 , de 29 de dezembro de 2008, pois foi a responsável pela Reforma da Educação Profissional, na educação superior. Ela redesenhou a rede federal de educação profissional e tecnológica então existente no Brasil, composta, de acordo com Otranto (2012), pelas seguintes instituições:

33 Centros Federais de Educação Tecnológica (CEFETs); 36 Escolas Agrotécnicas Federais (EAFs); 32 Escolas Vinculadas às Universidades Federais; uma Universidade Tecnológica Federal e uma Escola Técnica Federal. Todos os CEFETs e grande parte das EAFs contavam com várias Unidades de Ensino Descentralizadas (UNEDs), que se constituíam em uma espécie de campus avançado dessas instituições. Somente os CEFETs já contavam, na época, com 58 UNEDs (OTRANTO, 2012, p. 204). 
Expansão da educação superior e a reforma da rede federal de educação profissional

Essas instituições foram "convidadas", aproximadamente um ano antes da promulgação da Lei $n^{\circ} 11$ 1.892, a aderir a um Instituto Federal de Educação, Ciência e Tecnologia (IFs), a ser criado. A discussão dessa "adesão" foi bastante tensa (OTRANTO, 2010, 2012), diversas instituições não quiseram mudar a condição emque se encontravam (os principais exemplos são os Cefetsdo Rio de Janeiro e Minas Gerais), mas o processo teve curso, sendo promulgada a já referidalei n 11 .892, de 29 de dezembro de 2008, que institucionalizou 38 IFs (compostos de diversos campi).

Pela Lei, os IFs são instituições que têm por finalidade ofertar educação profissional e tecnológica em todos os níveis e modalidades e promover a integração e a verticalização da educação profissional, desde a educação básica até a educação superior, otimizando a infraestrutura física, os quadros de pessoal e os recursos de gestão. $\bigcirc$ texto legal também destaca que o IF deve realizar e estimular a pesquisa aplicada, a produção cultural, o empreendedorismo, o cooperativismo, e promover a produção, o desenvolvimento e a transferência de tecnologias sociais. Deve orientar sua oferta formativa em benefício da consolidação e fortalecimento dos arranjos produtivos, sociais e culturais locais, a partir de mapeamento das potencialidades de desenvolvi86 mento socioeconômico e cultural, em cada Instituto Federal (OTRANTO, 2010).

É preciso destacar, novamente, que os 38 IFs não são propriamente novas instituições. Eles surgem da "adesão" de antigos Cefets; Escolas Agrotécnicas e escolas vinculadas às Universidades Federais e aí reside um primeiro problema: estas instituições, em sua grande maioria,...

[...] não estavam preparadas para sua transformação em instituições de educação superior, multicampi, com todas as funções, direitos e deveres de uma universidade, com oferecimento da graduação, licenciatura e pós-graduação, atividades de pesquisa e extensão, além de outras não exigidas para as universidades, mas obrigatórias para os Institutos Federais, tais como: o ensino médio, técnico e educação de jovens e adultos [EJA] (OTRANTO, 201 1, p. 12).

Todo esse hibridismo aliado à forte expansão, e sem o suporte financeiro e humano necessário, é digno de preocupação e crítica de analistas da área. 
trabalho do docente que atua nessa rede é outro problema grave, pois, apesar dos IFs terem recebido novos docentes, na maioria das instituições o número ainda é insuficiente. De acordo com matéria publicada por Saldaña:

Auditoria do Tribunal de Contas da União (TCU) na rede de Institutos Federais de Educação, Ciência e Tecnologia mostra que faltam quase 8 mil professores, o equivalente a $20 \%$ dos profissionais necessários. $O$ déficit atinge toda a rede de 442 campi em funcionamento no país (SALDANA, 2013, p.1).

A carência de profissionais tem obrigado muitos docentes a ministrar aulas nos dois níveis. E aqui o problema é duplo. Por um lado, "[... ] os docentes mais antigos, especializados em ministrar aulas para o ensino médio, são alçados à categoria de professores da educação superior de um semestre para o outro" (OTRANTO, 2012, p. 220). Esse fato geratanto um ensino improvisado, com sério risco de rebaixamento da qualidade, como insegurança e dificuldade de adaptação à nova realidade da parte dos professores. Por outro lado, os docentes novos, em especial, os concursados nos padrões exigidos para as universidades federais - afinal, os IFstêm plena equivalência com as universidades - chegam às instituições com aspirações que, salvo exceções, não são afeitas ao ensino médio, e aos estudantes da EJA. "Como precisam, também, oferecer atividades de pesquisa e extensão, sentem-se prejudicados e reagem negativamente à proposta de lecionar fora do nível superior" (OTRANTO, 2012, p. 220).

quadro sinteticamente exposto no parágrafo precedente é a ponta de um profundo iceberg, pois revelaos conflitos e tensões que vêm marcando as relações interpessoais nos IFs e os reflexos negativos quecarreiam para o campo pedagógico. Por outro lado, permite pensar sobre a hierarquia existente entre áreas e campos do saber, entre os diversos níveis de ensino e sobre osestigmas em relação à formação de trabalhadores, particularmente no que tange à educação de jovens e adultos. Para Otranto (2012), tem sido um desafio encontrar professores que queiram trabalhar noProeja:

Lecionar para jovens e adultos vem sendo visto como uma atividade "menor" dentro doslFs. Alguns docentes se sentem desprestigiados quando são obrigados a trabalhar com essas turmas. [...] Muitos dos docentes pesquisados consideram "um castigo" trabalhar com EJA. Essa talvez seja uma das variáveis que, aliada à oferta de 
Expansão da educação superior e a reforma da rede federal de educação profissional

cursos que não levam em conta as necessidades do alunado, têm dificultado a obtenção de resultados positivos no Proeja oferecido pelos IFs, dificultado a permanência dos estudantes e ampliado, drasticamente, os índices de evasão (OTRANTO, 2012, p. 220-2211.

Outra preocupação que deve estar presente na análise dos IFs, refere-se à obrigatoriedade do oferecimento das licenciaturas e capacitação pedagógica de professores, em instituições que, na maioria das vezes, não contam, em seus quadros, com docentes licenciados e, portanto, com formação pedagógica e com tradição de pesquisa no campo da formação docente.

Por fim, a estreita articulação com os setores produtivos, principalmente na proposta de geração e adaptação de soluções técnicas e tecnológicas, e na oferta formativa, em benefício dos arranjos produtivos locais é altamente preocupante quanto às possibilidades de uma educação superior crítica e humanizadora (OTRANTO, 2010).

\section{Considerações finais}

Assiste-se a um inegável quadro de expansão da educação superior no país. Levando em conta as matrículas, tem-se a seguinte situação: entre 1995 e 2013 (última coleta do Censo da Educação Superior), ocorreu um crescimento no número de matrículas presenciais e à distância de aproximadamente $315 \%$. Trata-se de um crescimento complexo que compreende, por um lado, um expressivo aumento de instituições de ensino superior (IES) com fins lucrativos, isto é, privado/mercantis. Por outro, ações do governo federal expandindo vagas e titulações nas instituições federais de ensino superior (IFES), por meio da multiplicação dos campi das IFES já existentes, da expansão do número de instituições. E, ainda, mediante programas de reestruturação do setor, como é o caso do Programa de Reestruturação e Expansão das Universidades Federais (Reuni) e da Rede Federal de Educação Profissional, Científica e Tecnológica.

Este texto abordou a Reforma da Rede Federal de Educação Profissional, Científica e Tecnológica, por entender que sua expansão representa, hoje, mais do que a criação de um novo modelo institucional, mas a principal expressão da atual política pública para a expansão da educação 
superior brasileira. A análise das matrículas em cursos de graduação presencial é reveladora. Em 2001 (data a partir da qual o Inep fornece dados sobre educação profissional e tecnológica), as matrículas dos Centros Tecnológicos correspondiam a 4,02\% da rede federal. Em 2013, as matrículas das 40 instituições federais de educação tecnológica (Cefet/MG, Cefet/RJ e os 38 IFs) já representavam 10,68\% das matrículas na rede federal.

A análise precedente bem como toda a divulgação da educação profissional nos meios de comunicação permite concluir, preliminarmente, que, hoje, o sistema federal de educação superior é composto de duas redes: a das universidades e a rede profissional. E, a despeito do que é proclamado, têm objetivos, funções e controles distintos, além de se destinarem a públicos também diferentes.

Além do pragmatismo, cuja inspiração advém das recomendações do Banco Mundial, que indica serem as universidades de pesquisa muito dispendiosas, além do marketing que a expansão da rede profissional proporciona, há que se arguir sobre interesses mais estruturais para a compreensão de uma aposta tão forte nesse novo modelo.

Uma hipótese bastante plausível é a de que essa reforma configura processos formativos e educativos que atendem (e reproduzem) o capitalismo e suas formas de alienação necessárias à sua manutenção, na atual conjuntura. Como já discutido neste texto, a educação constrói-se, historicamente, à luz das demandas de valorização do capital, para o que os processos de capacitação ou disciplinamento da força de trabalho são vitais.

A argumentação de Kuenzer (2007, p. 1 165) é esclarecedora sobre esse aspecto. A autora parte da premissa de que a dualidade estrutural da educação, embora negada discursivamente na acumulação flexível, "não se supera, mantendo-se e fortalecendo-se, a partir de uma outra lógica", assim explicada:

As empresas para enfrentarem a competição, assegurando razoável margem de lucro, mantêm um núcleo duro de trabalhadores estáveis, com boas condições de trabalho, política generosa de benefícios e oportunidades de qualificação permanente, para assegurar capacidade de adaptação a novas exigências do trabalho, inclusive mobilidade geográfica. [Todavia], para além deste núcleo central, temos os grupos periféricos, compostos por trabalhadores cujas competências são facilmente encontradas no mercado e 
Expansão da educação superior e a reforma da rede federal de educação profissional

por toda a sorte de trabalhadores temporários e subcontratados, que apresentam baixa qualificação e alta rotatividade, uma vez que são incluídos/excluídos de ocupações precarizadas e intensificadas ao sabor das necessidades do mercado. Neste caso, a flexibilidade resulta da permanente movimentação de uma força de trabalho desqualificada, ocupada em tipos diversificados de trabalho precarizado, consumida predatoriamente ao longo das cadeias produtivas, onde e pelo tempo que se fizer necessária (KUENZER, 2007, p. 1 164).

Os profissionais do núcleo central são submetidos, permanentemente, a processos de formação e capacitação, mantém uma relação mais orgânica com o conhecimento produzido, tanto na formação inicial como na continuada. Isto thes confere a possibilidade "de enfrentamento de situações complexas, ou eventos [bem como]a flexibilidade para dar conta da dinamicidade dos processos de trabalho." (KUENZER, 2007, p. 1 164).Para os demais...,

[...] há uma aparente disponibilização das oportunidades educacionais, por meio de múltiplas modalidades e diferentes naturezas, que se caracterizam por seu caráter desigual e, na maioria das vezes, meramente certificatório, que não asseguram domínio de conhecimentos necessários ao desenvolvimento de competências cognitivas complexas vinculadas à autonomia intelectual, ética e estética (KUENZER, 2007, p. $1170-1171$ ).

A realidade educacional (simplificada e de qualidade discutível), oferecida para os grupos periféricos, já era bem conhecida no ensino superior privado-mercantil. Agora, diante da inevitável expansão do ensino superior público, o modelo invade a rede federal, com o Programa de Reestruturação e Expansão das Universidades Federais (Reuni) e com a reforma da educação profissional e institucionalização dos Institutos Federais de Educação, Ciência e Tecnologia. Constituem-se em políticas que desviam o direito à educação para o direito à certificação de escolaridade. Adicionalmente, cabe registrar que a reforma da rede profissional sugere maiores sucessos no que tange ao atendimento dos objetivos hegemônicos, pois tem uma relação mais orgânica com os "arranjos produtivos locais".

Por fim, todo esse dinamismo distancia a expansão da educação superior em curso da bandeira da "universalização" e a aproxima daquilo que 
Bruno (201 1) define como "massificação": um processo de universalização que reduz a formação às necessidades estritas do mercado de trabalho!

\section{Referências}

BANCO MUNDIAL. Construir sociedades del conocimiento: nuevos desafios para la educación terciária. Washington: Banco Internacional de Reconstrucción y Fomento/Banco Mundial, 2003.

BRASIL. Decreto-lei n 7.566, de 23 de Setembro de 1909. Cria nas capitais dos Estados da República Escolas de Aprendizes Artífices, para o ensino profissional primário e gratuito. Diário Oficial [da] República Federativa do Brasil, Poder Executivo, Rio de Janeiro, DF, Seção 1, p. 6975, 26 set. 1909.

Lei n $^{\circ} \mathbf{5 . 5 4 0}$, de 28 de novembro de 1968. Fixa normas de organização e financiamento do ensino superior e sua articulação com a escola média, e dá outras providências. Disponível em: <http://www2.camara.leg.br/legin/fed/lei/1960-1969/lei-5540-28-novembro-1968-359201-publicacaooriginal-1-pl.html>. Acesso em: 25 jan. 2015.

Congresso Nacional. Lei no 8.948, de 8 de dezembro de 1994. Dispõe sobre a instituição do Sistema Nacional de Educação Tecnológica e dá outras providências. Diário Oficial [da] República Federativa do Brasil, Brasília, DF, 9 dez. 1994. Seção 1, p. 18.882.

Congresso Nacional. Lei n 9.394, de 20 de dezembro de 1996. Estabelece as Diretrizes e Bases da Educação Nacional. Diário Oficial [da] República Federativa do Brasil, Brasília, DF, 23 dez. 1996. Seção 1, p. 27.833. (n² 248).

Decreto $n^{\circ} 2.208$, de 17 de abril de 1997. Regulamenta o parágrafo 20 do art. 36 e os artigos 39 a 42 da Lei n 9.394, de 20 de dezembro de 1996, que estabelece as diretrizes e bases da educação nacional. Diário Oficial [da] República Federativa do Brasil, Poder Executivo, Brasília, DF, 18 abr. 1997. Seção 1, p. 7760.

Decreto $n^{\circ} \mathbf{5 . 1 5 4}$, de 23 de julho de 2004. Regulamenta $\circ \S 2^{\circ}$ do art. 36 e os arts. 39 a 41 da Lei $n^{\circ}$ 9.394, de 20 de dezembro de 1996, que estabelece as diretrizes e da educação nacional e dá outras providências. Disponível em: <http://www. planalto.gov. br/ccivil_03/_ato20042006/2004/decreto/d5 154.htm>. Acesso em: 10 ago. 2014.

Decreto $n^{\circ} 5.225$, de $1^{\circ}$ de outubro de 2004a. Altera dispositivos do Decreto $n^{\circ}$ 3.860, de 9 de julho de 2001, que dispõe sobre a organização do ensino superior e a avaliação de cursos e instituições, e dá outras providências. Diário Oficial [da] República Federativa do Brasil, Poder Executivo. Brasília, DF, 4 out. 2004. Seção 1, p. 5. 
Expansão da educação superior e a reforma da rede federal de educação profissional

Congresso Nacional. Lei n 11 .892, de 29 de dezembro de 2008. Institui a Rede Federal de Educação Profissional Científica e Tecnológica e dá outras providências. Diário Oficial [da] República Federativa do Brasil, Brasília, DF, 30 dez. 2008. Seção 1, p. 1.

Lei $\mathbf{n}^{\circ}$ 12.513, de 26 de outubro de 2011. Institui o Programa Nacional de Acesso ao Ensino Técnico e Emprego (Pronatec); altera as Leis no 7.998, de 11 de janeiro de 1990, que regula o Programa do Seguro-Desemprego, o Abono Salarial e institui o Fundo de Amparo ao Trabalhador (FAT), no 8.212, de 24 de julho de 1991, que dispõe sobre a organização da Seguridade Social e institui Plano de Custeio, no 10.260, de 12 de julho de 2001, que dispõe sobre o Fundo de Financiamento ao Estudante do Ensino Superior, e no 11.129, de 30 de junho de 2005, que institui o Programa Nacional de Inclusão de Jovens (Projovem); e dá outras providências. Disponível em: < http://www.planalto.gov.br/ ccivil_03/_ato2011-2014/2011/lei/l12513.htm>. Acesso em: 25 ago. 2014.

MEC/INEP. Sinopses estatísticas do censo da educação superior: 1995 a 2014. Brasília: MEC. Disponível em: <http://www.inep.gov.br/superior/censosuperior/sinopse/ default.asp>. Acesso em: 10 jan. 2015.

BRUNO, Lúcia. Educação e desenvolvimento econômico no Brasil. Revista Brasileira de Educação, Rio de Janeiro, v. 16, n. 48,p.545-561, set./dez. 2011.

92 FRIGOTTO, Gaudêncio. A polissemia da categoria trabalho e a batalha das ideias nas sociedades de classe. Revista Brasileira de Educação, Rio de Janeiro, v. 14, n. 40, p. 168194, jan./abr.2009. Disponível em: <http://www.scielo.br/scielo.php?pid=S14132478 $2009000100014 \&$ script=sci_arttext>. Acesso em: 10 jun. 2014.

FRIGOTTO, Gaudêncio; CIAVATTA, Maria. Perspectivas sociais e políticas da formação de nível médio: avanços e entraves nas suas modalidades. Educação \& Sociedade, Campinas, v. 32, n. 116, p. $619-638$, jul./set. 2011.

HARVEY, David. A condição pós-moderna. São Paulo: Loyola, 1992.

KUENZER, Acácia Zeneida. Da dualidade assumida à dualidade negada: o discurso da flexibilização justifica a inclusão excludente. Educação \& Sociedade, Campinas, v. 28, n. 100, p. 11 153-1 178, out. 2007.

KUENZER, Acácia Zeneida; GRABOWSKI, Gabriel. Educação profissional: desafios para a construção de um projeto para os que vivem do trabalho. Perspectiva, Florianópolis, v. 24, n. 1, p. 297-318, jan./jun. 2006.

LIMA FILHO, Domingos Leite. A "era tecnológica" entre a realidade e a fantasia: reflexões a partir dos conceitos de trabalho, educação e tecnologia em Marx. Revista HISTEDBR, Campinas, p. 83-92, ago.2010. (Número especial). 
Trabalho docente na educação profissional e tecnológica e no PROEJA. Educação \& Sociedade, Campinas, v. 32, n. 116, p. 725-743, jul./set. 2011.

LUKÁCS, György. Ontologia do ser social: a falsa e a verdadeira ontologia de Hegel. Tradução Carlos Nelson Coutinho. São Paulo: Livraria de Ciências Humanas, 1979.

MANCEBO, Deise. Diversificação do ensino superior no Brasil e qualidade acadêmico-crítica. In: OLIVEIRA, João Ferreira de; CATANI, Afrânio Mendes; SILVA JÚNIOR, João dos Reis (Org.). Educação superior no Brasil: tempos de internacionalização. São Paulo: Xamã, 2010.

MARX, Karl. O capital. São Paulo: Abril Cultural, 1983.

MÉSZÁROS, István. Marx: a teoria da alienação. Rio de Janeiro: Zahar, 1981.

OTRANTO, Celia Regina. Criação e implantação dos Institutos Federais de Educação, Ciência e Tecnologia -IFETs. Revista Retta, Seropédica,v. 1, n. 1, p. 89-108, jan./jun. 2010.

A política de educação profissional do Governo Lula: novos caminhos da educação superior. In: REUNIÃO ANUAL DA ANPEd, 34; 2011 , Natal. Anais... Natal: Associação Nacional de Pós-Graduação e Pesquisa em Educação, 2011. Disponível em:<http://34reuniao.anped.org.br/images/trabalhos/GT1 1/GT1 131 5\%20int.pdf>. Acesso em: 01 ago. 2012.

Reforma da educação profissional no Brasil: marcos regulatórios e desafios. Revista Educação em Questão, Natal, v. 42, n. 28, p. 199-226, jan./abr. 2012.

PETEROSSI, Helena Gemignani. Educação e mercado de trabalho: análise crítica dos cursos de tecnologia. São Paulo: Loyola, 1980.

SALDAÑA, Paulo. Institutos federais têm déficit de 8 mil professores, revela auditoria do TCU. Estado de São Paulo, São Paulo, 26 mar. 2013. Disponível em:<http://www.estadao. $\mathrm{com} . \mathrm{br} /$ noticias/geral, institutos-federais-tem-deficit-de-8-mil-professores-revela-auditoria-do-tcu-imp-, $1013269>$ Acesso em: 28 mar. 2013.

SCHULTZ, Theodore. O capital humano. Rio de Janeiro: Zahar, 1973.

SIQUEIRA, Ângela Carvalho de. Organismos internacionais, gastos sociais e reforma universitária do governo Lula. In: NEVES, Lúcia Maria Wanderley (Org.). A reforma universitária do governo Lula: reflexões para o debate. São Paulo: Xamã, 2004.

SOUSA, José Vieira. Expansão dos cursos superiores de tecnologia no Brasil entre 1997 e 2011 . In: SOUSA, José Vieira (Org.). Educação superior: cenários, impasses e propostas. Campinas: Editora Autores Associados, 2013. 
WORLD BANK. Higher education: the lessons of experience. Washington, DC: The World Bank, 1994.

Education sector strategy. Washington, D.C.: The World Bank Group World, Human Development Network, 1999.

Profa. Dra. Deise Mancebo Universidade do Estado do Rio de Janeiro Instituto de Psicologia Programa de Pós-graduação em Políticas Públicas e Formação Humana | PPFH Pesquisadora da Rede Universitas | $\mathrm{Br}$ Coordenadora do Observatório da Educação "Políticas de Expansão da Educação Superior no Brasil" E-mail | deise.mancebo@gmail.com

Prof. Dr. João dos Reis Silva Júnior Livre Docente na Universidade de São Paulo

Universidade Federal de São Carlos Departamento de Educação Programa de Pós-Graduação em Educação Visiting Professor at Arizona State University (2014-2015) Coordenador do Grupo de Pesquisa em Economia Política da Educação, Estética e Formação Humana Pesquisador da Rede Universitas | $\mathrm{Br}$ Coordenador-adjunto do Observatório da Educação "Políticas de Expansão da Educação Superior no Brasil" Email | jr@pesquisador.cnpq.br

Recebido 11 set. 2014 Aceito 15 dez. 2014 